\title{
Knowledge and practice in the management of asymptomatic hyperuricemia among primary health care physicians in Jeddah, Western Region of Saudi Arabia
}

\author{
Norah A. Alqarni, MBBS, Abdul H. Hassan, MBBCh (Alexandria).
}

\begin{abstract}



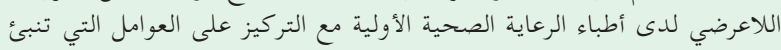



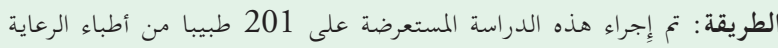

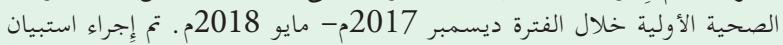



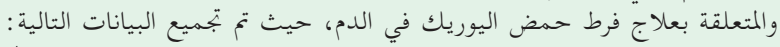

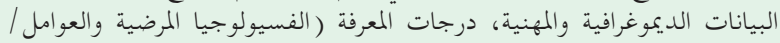

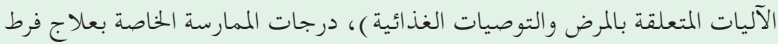





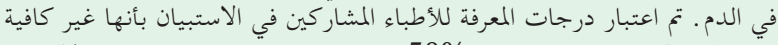

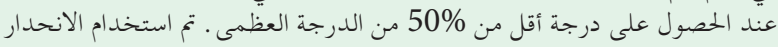



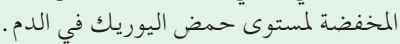

النتائج: أظهرت درجات الاستبيان وجود معرفة صحيحة بين 39.8\% من 32.8\% ومنارسة



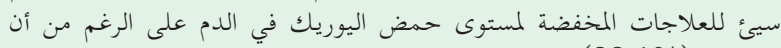

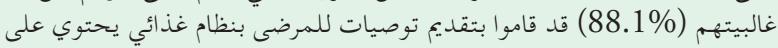

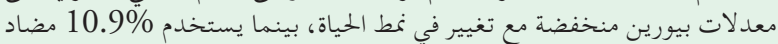

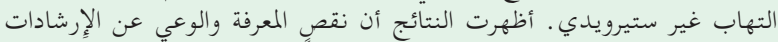

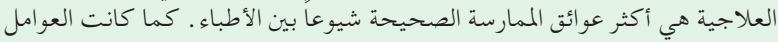

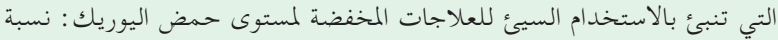

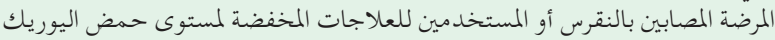

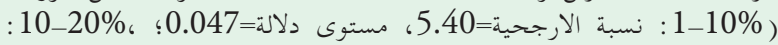

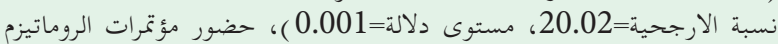

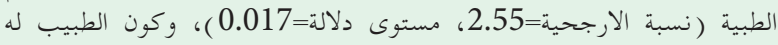


دلالة=0.026)

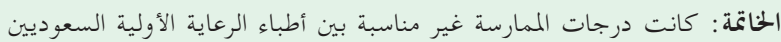

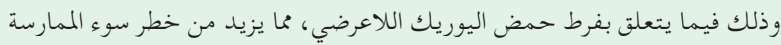

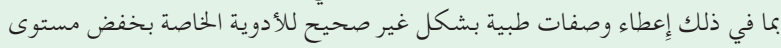
حمض اليوريك في الدم ومضادادات الالتهاب.
\end{abstract}

Objectives: To assess knowledge and practice levels in asymptomatic hyperuricemia $(\mathrm{AH})$ and investigate predictors of urate-lowering therapy (ULT) misprescribing among primary health care (PHC) physicians.
Methods: A cross-sectional study was conducted among 201 PHC physicians from December 2017 to May 2018. A based clinical guidelines for hyperuricemia management from American Professional Organizations, a semi-structured questionnaire was administered to collect demographic and professional data; knowledge and practice levels in management of $\mathrm{AH}$; and barriers to the management of hyperuricemia and gout, with focus of the misprescribing of ULT in AH. A 2-stage stratified sampling technique was used to select $4 \mathrm{PHC}$ centers were from each of the 5 advisory sectors in Jeddah, Kingdom of Saudi Arabia; and to recruit a minimum of 10 eligible participants per primary health care center (PHCC). Binary logistic regression was used to analyze predictors of ULT misuse in AH.

Results: Only $32.8 \%$ participating physicians had adequate knowledge about $\mathrm{AH}$. Regarding practice, while majority $(88.1 \%)$ correctly recommended a lowpurine diet and lifestyle changes to patients, almost half misprescribed ULT and $10.9 \%$ misprescribed nonsteroid anti-inflammatory drugs. Lack of knowledge and awareness about guidelines were the most frequently selfreported barriers to adequate practice. Predictors of ULT misuse included the percentage of patients having gout (1$10 \%$ : OR=5.40, $p=0.047)$ or receiving ULT $(>10-20 \%$ : $\mathrm{OR}=20.02, p=0.001)$ among patients seen in clinic, attendance of rheumatology conferences $(\mathrm{OR}=2.55$, $p=0.017$ ), and having a close relative with hyperuricemia or gout $(\mathrm{OR}=2.45, p=0.026)$.

Conclusion: There are inadequate levels of knowledge regarding $\mathrm{AH}$ among Saudi PHC physicians increasing risk of malpractice including misprescription of ULT and anti-inflammatory medications.

Saudi Med J 2018; Vol. 39 (12): 1218-1225 doi: 10.15537/smj.2018.12.23715

From the Joint Program of Family Medicine (Alqarni), King Fahad Armed Forces Hospital, and from the International Medical Center Hospital (Hassan), Jeddah, Kingdom of Saudi Arabia.

\section{Received 24th September 2018. Accepted 4th November 2018.}

Address correspondence and reprint request to: Dr. Norah A. Alqarni, Joint Program of Family Medicine, King Fahad Armed Forces Hospital, Jeddah, Kingdom of Saudi Arabia. E-mail: norah.a.algarni@hotmail.com ORCID ID: orcid.org/0000-0002-6236-5238 
symptomatic hyperuricemia $(\mathrm{AH})$ is defined Aas serum uric acid level $>6 \mathrm{mg} / \mathrm{dL}$ without the occurrence of specific symptoms such as gout and renal stones. ${ }^{1}$ This level corresponds to a significantly increased lifelong risk of occurrence of gout and matches the recommended target of urate-lowering drugs (ULDs) among gouty persons. ${ }^{2}$ Asymptomatic hyperuricemia is a general condition in men and is positively correlated with age and weight gain in both genders. ${ }^{3}$ Epidemiological studies have reported increased incidence of hyperuricemia in recent years. Possible factors include increasing prevalence of obesity and metabolic disorders, along with changes in dietary habits, particularly greater consumption of purinecontaining foods and sugar-sweetened soft drinks. ${ }^{3-5}$ The pathophysiological mechanisms of $\mathrm{AH}$ involve overproduction of urate, inefficient urate excretion by kidneys, or both. ${ }^{6}$

Above a certain threshold, a fraction of soluble monosodium urate crystallizes and accumulates in the synovial fluid or other soft tissues; this leads to gouty arthritis attacks and chronic gout and joint damage. ${ }^{7}$ Furthermore, $\mathrm{AH}$ is associated with higher risk of hypertension, chronic kidney disease, coronary artery disease, diabetes, and insulin resistance syndrome. ${ }^{8-11}$

Unfortunately, there is a lack of consensus about the definition and management of $\mathrm{AH}$, thus hindering understanding of this condition among both physicians and patients. ${ }^{2}$ In 2012, the American College of Rheumatologists (ACR) issued guidelines for the management of gout; however, no specific therapeutic measure was recommended for $\mathrm{AH}$, even though it is a major precursor of gout and is frequently associated with subclinical deposition of urate in joints. ${ }^{2-15}$ The American College of Physicians (ACP) in turn published recommendations for the management of acute and recurrent gout; they advised against the prescription of ULT after a first gout attack and recommended caution in initiating prophylactic ULT using in patients with recurrent gout attacks. These cautions are related to the lack of evidence regarding treatment efficacy in situations with infrequent gout flares and concerns about side effects. ${ }^{12}$

In addition to the unclear ACR and ACP guidelines of $\mathrm{AH}$ management, the literature contains conflicting reports regarding the usefulness of treating $\mathrm{AH}$, both to reduce the risk of progression to gout and to prevent

Disclosure. Authors have no conflict of interests, and the work was not supported or funded by any drug company. complications such as renal deposits of urate crystals. ${ }^{15-19}$ Cost-benefit analyses for both symptomatic treatments and ULT should be taken into consideration. ${ }^{14}$

Consequently, management of $\mathrm{AH}$ may be highly inconsistent, especially among non-specialists such as PHC physicians. This entails a high risk of malpractice and misprescription, which may in turn lead to high morbidity and expenditures. Thus, this study was designed to provide insight into the current knowledge and practice levels regarding $\mathrm{AH}$ among physicians in Kingdom of Saudi Arabia, and to investigate factors and predictors of ULT misprescribing along with perceived barriers to management of $\mathrm{AH}$.

Methods. During the period December 2017 to May 2018, we conducted a cross-sectional study among physicians practicing as family medicine doctors (Family Medicine Board graduates) or general practitioners or in other specialties (internal medicine, obstetricsgynecology and geriatrics specialists) in the Ministry of Health $(\mathrm{MOH})$ PHCCs in Jeddah, Kingdom of Saudi Arabia. Jeddah contains 46 PHCCs distributed across 5 geographic sectors. Physicians of both genders, all ages, and all nationalities practicing in MOH PHCCs for at least one year were eligible. The study was approved by the Directorate of Health Affairs, $\mathrm{MOH}$ in Jeddah, kingdom of Saudi Arabia. All the data obtained from the study were blinded and thus, informed consent was not required.

A 2-stage stratified sampling technique was used in this study. Stage 1: 4 PHCCs were selected from each of the 5 sectors using a simple random sampling technique. Stage 2: convenience sampling was used to recruit eligible physicians present at the time of data collection, with a minimum of 10 participants per PHCC.

Data collection. The semi-structured Englishlanguage questionnaire included the following parts: Demographic and professional information such as age, gender, specialty, years of practice, and average number of patients seen per day; perceptions about $\mathrm{AH}$, including its definition, correlation with gout, and awareness about its major causes; knowledge about $\mathrm{AH}$ (subscales included pathophysiology, common etiological factors, and dietary recommendations for people with hyperuricemia); level of practice in $\mathrm{AH}$ management (subscales included history taking, physical examination, evaluation of comorbid conditions, complementary investigations, and treatment/ management of $\mathrm{AH}$, including medication prescribing patterns); perceived barriers to the management of hyperuricemia. The questionnaire was developed based 
on hyperuricemia management guidelines from the ACR and the ACP. ${ }^{12,20}$ Two rheumatologists and an epidemiologist reviewed the questionnaire items for validity. The questionnaire was tested among 20 eligible participants to assess its clarity, and internal consistency was measured using Cronbach's alpha.

Scoring system. The knowledge part of the questionnaire allowed calculation of a knowledge score; related questions had incorrect (score $=0$ ) or correct (score $=1$ ) answer options. The knowledge score was calculated as the number of correct answers (range: 0 -40). Further, subscores were calculated on knowledge subscales (pathophysiology factors and mechanisms, dietary recommendations) to explore the most deficient areas.

Data collection technique. Participating PHCCs were visited during regular working hours. Physicians who were present during the visit were invited to participate in peer-to-peer interviews lasting 18-25 minutes.

Statistical methods. Data were coded, entered, and analyzed using Statistical Package for Social Science (SPSS) version 21 for Windows (IBM Corp., Armonk, NY, USA). Knowledge score distribution was analyzed using Kolmogorov-Smirnov and Shapiro-Wilk tests concluding to non-normal distribution. Adequate knowledge was defined using an assumed cut-off $>20 / 40$ correct answers (50\% of the maximum possible score). Chi-squared tests were used to analyze factors associated with misuse of ULT. Multivariate binary regression was used to analyze the predictors of and independent risk factors for ULT misuse in AH. A p-value $<0.05$ was considered significant.
Results. The study included 201 PHC physicians; $66.2 \%$ were female, $65.2 \%$ were married, and mean age was $34.53 \pm 6.82$ years. Of the participants, $58.7 \%$ were family medicine specialists and $28.4 \%$ were general practitioners. The majority (59.2\%) had more than 5 years of practice. More than half of the participants (54.2\%) had more than 20 patients per day. The average percentage of patients with gout or receiving ULT was $12.79 \%$, and $64.7 \%$ reported that $\leq 10 \%$ of their patients had gout or received ULT (results not presented).

Questionnaire internal consistency. As shown in Table 1, the overall knowledge scale showed high internal consistency (Cronbach's alpha=0.837). Knowledge subscales rated highly as well (pathophysiology: 0.767, factors/mechanisms: 0.756, and dietary recommendations: 0.887$)$. Overall internal consistency for the practice scale was very high (Cronbach's alpha $=0.972$ ), ranging from 0.830 for history taking to 0.961 for comorbidity evaluation. However, treatment management scale showed negative value of Cronbach's alpha $(-0.920)$ because one of the items had a negative covariance.

Perceptions about AH. Table 2 shows that among participating physicians, $64.7 \%$ correctly identified $\mathrm{AH}$ and gout as being different but related diagnoses; $84.6 \%$ chose the correct $\mathrm{AH}$ definition, $71.1 \%$ correctly identified urate hyperproduction, and $55.2 \%$ correctly identified decreased renal excretion as being possible mechanisms of hyperuricemia.

Knowledge and practice levels regarding $A H$. Table 2 showed that mean knowledge scores (18.1) was generally low, with only $32.8 \%$ of participants having

Table 1 - Internal consistency of the questionnaire and levels of knowledge and practice regarding asymptomatic hyperuricemia among primary health care physicians $(\mathrm{N}=201)$.

\begin{tabular}{|c|c|c|c|c|c|c|}
\hline Scale/subscale & $\begin{array}{l}\text { No. } \\
\text { items }\end{array}$ & $\begin{array}{l}\text { Cronbach's } \\
\text { alpha }\end{array}$ & $\begin{array}{l}\text { Cronbach's alpha } \\
\text { without item, range }^{\dagger}\end{array}$ & Mean \pm SD & Cutoff & Adequacy rate $\left.{ }^{\S} \%\right)$ \\
\hline \multicolumn{7}{|l|}{ Knowledge } \\
\hline $\begin{array}{l}\text { Pathophysiology } \\
\text { Factors/mechanisms } \\
\text { Dietary recommendations } \\
\text { Overall knowledge }\end{array}$ & $\begin{array}{l}12 \\
13 \\
15 \\
40\end{array}$ & $\begin{array}{l}0.767 \\
0.756 \\
0.887 \\
0.837\end{array}$ & $\begin{array}{l}0.732,0.787 \\
0.721,0.774 \\
0.873,0.892 \\
0.825,0.847\end{array}$ & $\begin{array}{l}6.21 \pm 2.40 \\
4.19 \pm 1.30 \\
7.66 \pm 3.08 \\
18.06 \pm 4.63\end{array}$ & $\begin{array}{r}6.0 \\
6.5 \\
7.5 \\
20.0\end{array}$ & $\begin{array}{r}47.3 \\
3.0 \\
62.7 \\
32.8\end{array}$ \\
\hline \multicolumn{7}{|l|}{ Practice } \\
\hline $\begin{array}{l}\text { History taking } \\
\text { Physical examination } \\
\text { Comorbidity evaluation } \\
\text { Complementary investigations } \\
\text { Treatment/management } \\
\text { Overall practice }\end{array}$ & $\begin{array}{c}8 \\
4 \\
9 \\
8 \\
6^{*} \\
35\end{array}$ & $\begin{array}{c}0.930 \\
0.954 \\
0.961 \\
0.948 \\
-0.920^{\ddagger} \\
0.972\end{array}$ & $\begin{array}{c}0.915,0.930 \\
0.930,0.959 \\
0.954,0.961 \\
0.937,0.951 \\
-1.026,-0.011 \\
0.970,0.974\end{array}$ & $\begin{array}{l}3.85 \pm 2.50 \\
1.63 \pm 1.60 \\
4.26 \pm 1.54 \\
5.18 \pm 1.47 \\
- \\
-\end{array}$ & $\begin{array}{l}4.0 \\
2.0 \\
4.5 \\
4.0 \\
- \\
-\end{array}$ & $\begin{array}{l}47.3 \\
41.3 \\
47.8 \\
74.6 \\
- \\
-\end{array}$ \\
\hline
\end{tabular}

${ }^{\ddagger}$ value is negative because one of the items had negative mean covariance. ${ }^{\dagger}$ gives the range of Cronbach's alpha values after exclusion of one item in a given subscale. ${ }^{*} 50 \%$ maximum theoretical score (No. items). ${ }^{\$}$ percentage of participants with score>cutoff. 
Table 2 - Perceptions about asymptomatic hyperuricemia including its definition, relationship with gout, and major mechanisms (N=201).

\begin{tabular}{lcr}
\hline Question & Answer options & $\mathbf{n}(\%)$ \\
\hline $\begin{array}{l}\text { In your opinion, asymptomatic hyperuricemia and gout } \\
\text { represent: }\end{array}$ & The same diagnosis & $22(10.9)$ \\
& Different related diagnoses & $130(64.7)$ \\
& Different unrelated diagnoses & $28(13.9)$ \\
& I do not know & $21(10.4)$ \\
According to your knowledge, what is the best definition of & Elevation of serum urate level without gout symptoms & $171(84.6)$ \\
asymptomatic hyperuricemia? & Elevation of serum urate level with mild gout symptoms & $22(10.9)$ \\
& Normal serum urate level with mild symptoms of gout & $6(3.0)$ \\
& Monoarticular gouty arthritis with normal serum urate level & $2(1.0)$ \\
& Incidental uric nephrolithiasis & $0(0.0)$ \\
According to your knowledge, what is/are the possible & Increased urate production & $143(71.1)$ \\
mechanism(s) of hyperuricemia? (multiple answers possible) & Decreased urate production & $7(3.5)$ \\
& Increased renal excretion of urate & $14(7.0)$ \\
& Decreased renal excretion of urate & $111(55.2)$ \\
& Increased production combined with decreased excretion & $58(28.9)$ \\
\hline
\end{tabular}

Because of missing data, some frequencies do not add up to $(\mathrm{N}=201)$.

adequate knowledge about $\mathrm{AH}$ by consideration of the used cutoffs. With respect of respective subscales, knowledge adequacy rates ranged from 3\% (factors/ mechanisms) to $62.7 \%$ (dietary recommendations); and practice adequacy rates ranged from $41.3 \%$ (physical examination) to $74.6 \%$ (complementary investigations). Management/treatment practice subscale was separately analyzed in and presented in Figure 1, showing that a majority of participants (88.1\%) would recommend a low-purine diet and lifestyle changes to patients with $\mathrm{AH}$, while $27.4 \%$ would prescribe short-term ULT and $21.9 \%$ would prescribe long-term ULT.

Barriers to practice regarding $A H$. Figure 2 illustrates that lack of knowledge about the guidelines was the most frequently reported barrier to adequate practice in $\mathrm{AH}$, followed by lack of awareness of the guidelines' existence and inadequate knowledge about the disease.

Factors associated with ULT misuse in AH. Among all participants, $48.8 \%$ declared using or recommended the use of short-term and or long-term ULT in AH. Table 3 presents factors associated with ULT misuse in AH. Misuse of ULT was less reported among young physicians $(p<0.001)$ and those with relatively short experience $(p<0.001)$ compared to their counterparts. Misuse was also associated with the percentage of patients having gout or receiving ULT, displaying an inversed U-shaped relationship, with highest rates of misuse observed among physicians who declared that $10-20 \%$ of their patients having gout or receiving ULT. Paradoxically, attendance of rheumatology conference and having a close relative with hyperuricemia or gout were associated with higher rates of ULT misuse, compared to their counterparts. Analysis of knowledge

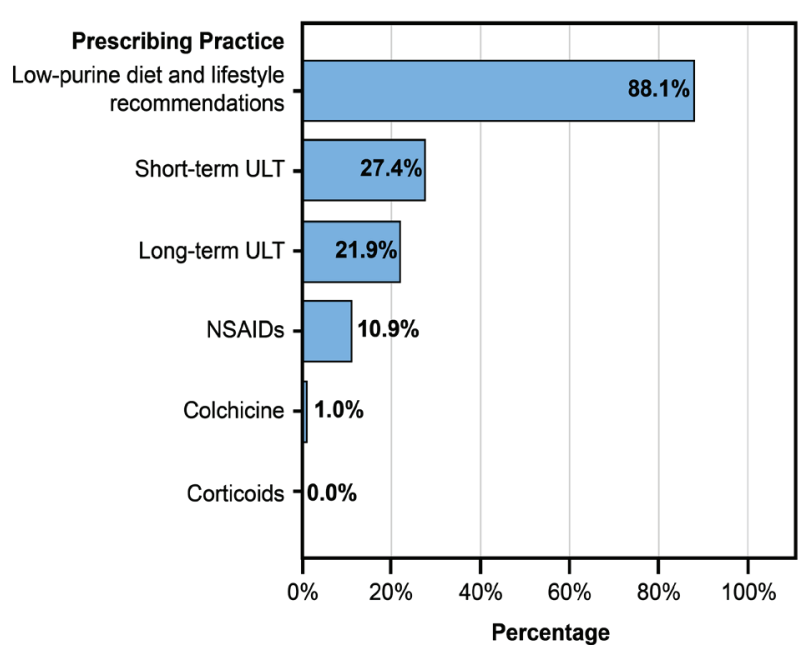

Figure 1 - Prescribing patterns in asymptomatic hyperuricemia among primary health care physicians $(\mathrm{N}=201)$. Bars represent the percentage of participants who would prescribe the given therapeutic option for patients with asymptomatic hyperuricemia. ULT - urate-lowering therapy, NSAIDs - nonsteroidal anti-inflammatory drugs.

score showed significant association of ULT misuse with knowledge about pathophysiology $(p=0.039)$ but not with overall knowledge $(p=0.513)$ or other knowledge subscales scores $(p>0.050)$.

Predictors of ULT misuse in AH. The risk of ULT misuse in $\mathrm{AH}$ was independently associated with the percentage of patients having gout $(1-10 \%: \mathrm{OR}=5.40$, $p=0.047$ ) or receiving ULT ( $>10-20 \%$ : OR=20.02, $p=0.001$ ), attendance of rheumatology conferences $(\mathrm{OR}=2.55, p=0.017)$, and having a close relative with hyperuricemia or gout $(\mathrm{OR}=2.45, p=0.026)$ (Table 4$)$. 




Figure 2 - Barriers to management of asymptomatic hyperuricemia among primary health care physicians $(\mathrm{N}=201)$. Bars represent the number of participants who declared that the given factor was a true), somewhat true, or false barrier.

Discussion. The clinical relevance of $\mathrm{AH}$ and whether it should be treated has long been controversial. ${ }^{6}$ Nevertheless, in accordance to ACR and ACP guidelines, physicians should be aware of hyperuricemia management practices, including clinical and etiological diagnosis, lifestyle and dietary recommendations, proper monitoring of serum urate levels, and screening for eventual complications. ${ }^{15,17,18,21}$ Nonetheless, some major discrepancies have been highlighted between ACP guidelines and recommendations published by other rheumatology expert panels, such as the ACR and the European League Against Rheumatism (EULAR); and these discrepancies result from differences in the fundamental approach. The ACP approach is focused on patient-perceived benefits and burdens and clinically-driven management strategy; while the rheumatology expert recommendations are based on a pathophysiological approach considering the chronicity and progressiveness of the disease with the subsequent disorders, which represents a more evidence-based approach. ${ }^{22}$

Findings of this study suggest a high prevalence of hyperuricemia and gout among patients visiting PHCCs, as one-third of the physicians estimated that more than $10 \%$ of their patients had gout or received ULT. Few epidemiological studies on gout and hyperuricemia in Kingdom of Saudi Arabia exist; Al-Arfaj, ${ }^{23}$ estimated the prevalence of hyperuricemia as $8.4 \%$ in 2001 . Since that time, prevalence may have increased in Kingdom of Saudi Arabia as it has worldwide, especially given increases in obesity and diseases associated with poor lifestyle and dietary habits. ${ }^{3-5}$
Approximately, one-half of the participating physicians were able to correctly define $\mathrm{AH}$ as elevation of serum urate level without presence of gout symptoms. However, knowledge about hyperuricemia and $\mathrm{AH}$ was overall poor to moderate, notably in factors/mechanisms underlying hyperuricemia (only 3\% adequacy).

Practice in AH was marked by high rate of ULT misuse, as almost half of the physicians declared that they would prescribe either short-term or long-term ULT for AH, which was predicted by several factors. In a 2014 Saudi study by Mustafa, ${ }^{6} 84.1 \%$ of physicians would recommend allopurinol treatment for $\mathrm{AH}$, suggesting a higher level of misprescription than seen here. Allopurinol prescription for $\mathrm{AH}$ is a frequent practice among United Kingdom's physicians as well. ${ }^{24}$ Further, ULT misprescribing may be associated with the lack of screening for medication interactions and inadequate follow-up; this increases the risk of severe side effects and complications. Other potentially misprescribed medicines advocated by physicians participating in this study included non-steroidal antiinflammatory drugs (NSAIDs) (10\%) and colchicine (1\%). These medications are indicated for pain during gout attacks or prophylactically in chronic gout whereas $\mathrm{AH}$ is by definition characterized by absence of clinical justification for such treatment. ${ }^{12,13}$

According to ACR and ACP guidelines, the sole therapeutic options warranted for $\mathrm{AH}$ are a low-purine diet and lifestyle changes; $88.1 \%$ of the physicians in this study concurred. In contrast, Mustafa, ${ }^{6}$ reported earlier that only $42.5 \%$ of physicians provided dietary advice for patients with AH. Dietary and lifestyle 
Table 3 - Factors associated with urate-lowering therapy misuse (N=201).

\begin{tabular}{|c|c|c|c|}
\hline \multirow[t]{2}{*}{ Parameter } & \multicolumn{2}{|c|}{ ULT misuse } & \multirow[t]{3}{*}{$P$-value } \\
\hline & No & Yes & \\
\hline & \multicolumn{2}{|c|}{ n $(\%)$} & \\
\hline \multicolumn{4}{|l|}{ Gender } \\
\hline Male & $31(45.6)$ & $37(54.4)$ & 0.251 \\
\hline \multicolumn{4}{|l|}{ Age (years) } \\
\hline $25-30$ & $54(73.0)$ & $20(27.0)$ & \multirow{3}{*}{$<0.001^{*}$} \\
\hline $31-40$ & $36(38.3)$ & $58(61.7)$ & \\
\hline$>40$ & $13(39.4)$ & $20(60.6)$ & \\
\hline \multicolumn{4}{|l|}{ Years of practice } \\
\hline $0-5$ & $59(72.0)$ & $23(28.0)$ & \multirow{4}{*}{$<0.001^{*}$} \\
\hline$>5-10$ & $23(39.0)$ & $36(61.0)$ & \\
\hline$>10-15$ & $9(25.7)$ & $26(74.3)$ & \\
\hline$>15$ & $12(48.0)$ & $13(52.0)$ & \\
\hline \multicolumn{4}{|l|}{ Specialty } \\
\hline General medicine & $26(45.6)$ & $31(54.4)$ & \multirow{3}{*}{$0.023^{*}$} \\
\hline Family medicine & $69(58.5)$ & 49 (41.5) & \\
\hline Other* & $8(30.8)$ & $18(69.2)$ & \\
\hline \multicolumn{4}{|c|}{ Number of patients seen per day } \\
\hline Up to 20 & $45(51.7)$ & $42(48.3)$ & \multirow{3}{*}{0.112} \\
\hline$>20-30$ & $35(44.3)$ & $44(55.7)$ & \\
\hline$>30$ & $20(66.7)$ & $10(33.3)$ & \\
\hline \multicolumn{4}{|c|}{ Percentage of patients having gout or receiving ULT } \\
\hline$<1 \%$ & $15(88.2)$ & $2(11.8)$ & \multirow{4}{*}{$<0.001^{*}$} \\
\hline $1-10 \%$ & $62(54.9)$ & $51(45.1)$ & \\
\hline$>10-20 \%$ & $9(17.0)$ & $44(83.0)$ & \\
\hline$>20 \%$ & $17(94.4)$ & $1(5.6)$ & \\
\hline \multicolumn{4}{|c|}{ Elective rotation in rheumatology } \\
\hline No & $84(52.2)$ & $77(47.8)$ & \multirow[b]{2}{*}{500} \\
\hline Yes & $18(46.2)$ & $21(53.8)$ & \\
\hline \multicolumn{4}{|c|}{ Rheumatology conference/meeting attendance } \\
\hline No & $72(65.5)$ & $38(34.5)$ & \multirow{2}{*}{$<0.001^{*}$} \\
\hline Yes & $30(33.3)$ & $60(66.7)$ & \\
\hline \multicolumn{4}{|c|}{ Personal history of hyperuricemia or gout } \\
\hline No & $91(49.5)$ & $93(50.5)$ & \multirow{2}{*}{0.139} \\
\hline Yes & $11(68.8)$ & $5(31.3)$ & \\
\hline Close relative with hyp & a or gout & & \\
\hline No & $54(75.0)$ & $18(25.0)$ & \\
\hline Yes & $48(37.5)$ & $80(62.5)$ & $<0.001^{*}$ \\
\hline Overall knowledge sco & & & \\
\hline Adequate $(\geq 20 / 40)$ & $36(54.5)$ & $30(45.5)$ & \\
\hline Inadequate $(<20)$ & $67(49.6)$ & $68(50.4)$ & 0.513 \\
\hline Pathophysiology know & & & \\
\hline Adequate $(\geq 6 / 12)$ & $56(58.9)$ & $39(41.1)$ & \\
\hline Inadequate $(<6)$ & $47(44.3)$ & $59(55.7)$ & $0.039^{*}$ \\
\hline Knowledge about facto & & & \\
\hline Adequate $(\geq 7.8 / 13)$ & $5(83.3)$ & $1(16.7)$ & \\
\hline Inadequate $(<7.8)$ & $98(50.3)$ & $97(49.7)$ & 0.110 \\
\hline Knowledge about diet & & & \\
\hline Adequate $(\geq 9 / 15)$ & $69(54.8)$ & $57(45.2)$ & \\
\hline Inadequate $(<15)$ & $34(45.3)$ & $41(54.7)$ & 0.196 \\
\hline
\end{tabular}

Table 4 - Predictors of urate-lowering therapy misuse in asymptomatic hyperuricemia $(\mathrm{N}=201)$.

\begin{tabular}{|c|c|c|c|c|}
\hline \multirow[t]{2}{*}{ Parameter } & \multicolumn{4}{|c|}{ ULT misuse } \\
\hline & OR & & $\mathrm{CI}$ & $P$-value \\
\hline \multicolumn{5}{|l|}{ Age (years) } \\
\hline $\begin{array}{l}25-30 \text { (ref) } \\
31-40 \\
>40\end{array}$ & $\begin{array}{l}- \\
1.66 \\
1.76\end{array}$ & $\begin{array}{c}- \\
0.54 \\
0.19\end{array}$ & $\begin{array}{c}- \\
5.09 \\
16.68\end{array}$ & $\begin{array}{l}0.669 \\
0.371 \\
0.621\end{array}$ \\
\hline \multicolumn{5}{|l|}{ Years of practice } \\
\hline $\begin{array}{l}0-5(\mathrm{ref}) \\
>5-10 \\
>10-15 \\
>15\end{array}$ & $\begin{array}{l}- \\
1.51 \\
2.14 \\
1.05\end{array}$ & $\begin{array}{l}- \\
0.48 \\
0.48 \\
0.10\end{array}$ & $\begin{array}{c}- \\
4.70 \\
9.51 \\
10.95\end{array}$ & $\begin{array}{l}0.696 \\
0.480 \\
0.316 \\
0.967\end{array}$ \\
\hline \multicolumn{5}{|l|}{ Specialty } \\
\hline $\begin{array}{l}\text { General medicine (ref) } \\
\text { Family medicine } \\
\text { Other }\end{array}$ & $\begin{array}{l}- \\
0.90 \\
1.55\end{array}$ & $\begin{array}{c}- \\
0.40 \\
0.43\end{array}$ & $\begin{array}{c}- \\
2.01 \\
5.66\end{array}$ & $\begin{array}{l}0.670 \\
0.790 \\
0.503\end{array}$ \\
\hline \multicolumn{5}{|c|}{ Percentage of patients having gout or receiving ULT } \\
\hline $\begin{array}{l}<1 \%(\mathrm{ref}) \\
1-10 \% \\
>10-20 \% \\
>20 \%\end{array}$ & $\begin{array}{c}- \\
5.40 \\
20.02 \\
0.37\end{array}$ & $\begin{array}{l}- \\
1.02 \\
3.20 \\
0.03\end{array}$ & $\begin{array}{c}- \\
28.50 \\
125.23 \\
5.14\end{array}$ & $\begin{array}{c}<0.001^{*} \\
0.047^{*} \\
0.001^{*} \\
0.462\end{array}$ \\
\hline \multicolumn{5}{|c|}{ Rheumatology conference/meeting attendance } \\
\hline $\begin{array}{l}\text { No (ref) } \\
\text { Yes }\end{array}$ & 2.55 & - & 5.52 & $\overline{-} 017^{*}$ \\
\hline \multicolumn{5}{|c|}{ Close relative with hyperuricemia or gout } \\
\hline $\begin{array}{l}\text { No (ref) } \\
\text { Yes }\end{array}$ & 2.45 & 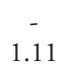 & 5.41 & $-\overline{-}$ \\
\hline \multicolumn{5}{|c|}{ Pathophysiology knowledge score } \\
\hline $\begin{array}{l}\text { Adequate }(\geq 6 / 12)(\mathrm{ref}) \\
\text { Inadequate }(<6)\end{array}$ & $\begin{array}{c}- \\
1.08 \\
\end{array}$ & $\begin{array}{c}- \\
0.50 \\
\end{array}$ & $\begin{array}{c}- \\
2.34 \\
\end{array}$ & $\begin{array}{c}- \\
0.840 \\
\end{array}$ \\
\hline $\begin{array}{r}\text { Multivariate binary } \\
\text { interval. ref - reference } \\
\text { lowering therapy. }\end{array}$ & $\begin{array}{l}\text { ression. } \\
\text { egory fo } \\
\text { atisticall }\end{array}$ & $\begin{array}{l}\text { - odds } \\
\text { culatio } \\
\text { nifican }\end{array}$ & $\begin{array}{l}\text { io, CI - c } \\
\text { f OR, UI } \\
\text { esult }(p<0\end{array}$ & $\begin{array}{l}\text { fidence } \\
\text { - urate- } \\
\text { 5). } \\
\end{array}$ \\
\hline
\end{tabular}

recommendations are crucial to reduce health risks associated with hyperuricemia, and include limiting intake of high-purine foods, as well as controlling obesity, smoking, and alcohol consumption. ${ }^{4,14,23}$

We observed that less than half (41.3-47.8\%) of physicians achieved adequate history taking, physical examination, and comorbidity evaluation in patients with $\mathrm{AH}$. Diagnosis of $\mathrm{AH}$ depends on ruling out conditions such as arthritis or nephrolithiasis that may evoke symptoms similar to gout, or even undiagnosed gout attacks. For the latter, diagnosis and management of gout, rather than $\mathrm{AH}$, is warranted. History taking also facilitates screening for family history of gout, which may uncover important genetic background factors. ${ }^{25}$ Furthermore, history taking enables physicians to rule out external causes of hyperuricemia such as urateelevating medications. ${ }^{12}$ Similarly, physical examination may detect signs of arthritis, tophi, synovitis, or any comorbidity (such as kidney disease, metabolic 
syndrome, or obesity) that may affect $\mathrm{AH}$ diagnosis or management. ${ }^{12,26,27}$ Complementary investigations may be helpful in detecting subclinical arthritis or urolithiasis (through imaging, namely ultrasound) or detecting urate overproduction (through measurement of urine uric acid levels). ${ }^{2,16}$

This study showed paradoxical association of attendance to rheumatology conference with higher risk of ULT misuse; which may be explained by physicians having gaps in rheumatology being more interested in related conferences. The other inconsistency association includes having a close relative with hyperuricemia which was predictive for higher risk of ULT misuse. Unfortunately, for both issues, the questionnaire does not include sufficient details to explain these inconsistencies.

Study limitations. Females, young doctors (up to 5 years of practice), and family physicians were relatively overrepresented in the sample. This could be due to selection bias, as there was some difficulty obtaining consent from relatively older physicians. The study questionnaire showed very good internal consistency in all scales/subscales. However, it should be further validated using the test-retest method and by measuring its reliability in different populations.

In conclusion, this study shed light on major gaps in knowledge and practice regarding $\mathrm{AH}$ among physicians in western Kingdom of Saudi Arabia, especially concerning factors leading to hyperuricemia and their respective mechanisms, as well as treatment prescribing patterns with high rate of ULT misuse. Lack of awareness and knowledge about international guidelines and inadequate knowledge about the disease were primary reasons for low confidence and practice levels among the surveyed physicians. Notably, physicians who attended conferences and meetings in rheumatology had significantly higher risk for ULT misuse. Combined, these observations suggest important gaps in formal training in hyperuricemia/ rheumatology, emphasizing the need for strengthened theoretical and clinical training to reduce the risk of malpractice, associated morbidity, and resulting costs.

Acknowledgment. The authors would like to thank all the physicians who participated in this study.

\section{References}

1. Bardin T. Hyperuricemia starts at 360 micromoles $(6 \mathrm{mg} / \mathrm{dL})$. Joint Bone Spine 2015; 82: 141-143.

2. Bardin T, Richette P. Definition of hyperuricemia and gouty conditions. Curr Opin Rheumatol 2014; 26: 186-191.
3. Rho YH, Zhu Y, Choi HK. The epidemiology of uric acid and fructose. Semin Nephrol 2011; 31: 410-419.

4. Kedar E, Simkin PA. A perspective on diet and gout. $A d v$ Chronic Kidney Dis 2012; 19: 392-397.

5. Chuang SY, Lee SC, Hsieh YT, Pan WH. Trends in hyperuricemia and gout prevalence: Nutrition and Health Survey in Taiwan from 1993-1996 to 2005-2008. Asia Pac J Clin Nutr 2011; 20: 301-308.

6. Mustafa $\mathrm{H}$. To treat or not to treat asymptomatic hyperuricemia. Saudi J Med Med Sci 2014; 2: 95-100.

7. Mandell BF. Clinical manifestations of hyperuricemia and gout. Cleve Clin J Med 2008; 75: S5-S8.

8. Choi HK, Curhan G. Independent impact of gout on mortality and risk for coronary heart disease. Circulation 2007; 116: 894-900.

9. Kim SY, Guevara JP, Kim KM, Choi HK, Heitjan DF, Albert DA. Hyperuricemia and coronary heart disease: a systematic review and meta-analysis. Arthritis Care Res (Hoboken) 2010; 62: 170-180.

10. Choi HK, Ford ES. Prevalence of the metabolic syndrome in individuals with hyperuricemia. Am J Med 2007; 120: 442-447.

11. Choi HK, Ford ES. Haemoglobin A1c, fasting glucose, serum C-peptide and insulin resistance in relation to serum uric acid levels--the Third National Health and Nutrition Examination Survey. Rheumatology (Oxford) 2008; 47: 713-717.

12. Khanna D, Fitzgerald JD, Khanna PP, Bae S, Singh MK, Neogi T, et al. 2012 American College of Rheumatology guidelines for management of gout. Part 1: systematic nonpharmacologic and pharmacologic therapeutic approaches to hyperuricemia. Arthritis Care Res (Hoboken) 2012; 64: 1431-1446.

13. Khanna D, Khanna PP, Fitzgerald JD, Singh MK, Bae S, Neogi T, et al. 2012 American College of Rheumatology guidelines for management of gout. Part 2: therapy and antiinflammatory prophylaxis of acute gouty arthritis. Arthritis Care Res (Hoboken) 2012; 64: 1447-1461.

14. Desideri G, Puig JG, Richette P. The management of hyperuricemia with urate deposition. Curr Med Res Opin 2015; 31: 27-32.

15. Campion EW, Glynn RJ, DeLabry LO. Asymptomatic hyperuricemia. Risks and consequences in the Normative Aging Study. Am J Med 1987; 82: 421-426.

16. Pineda C, Amezcua-Guerra LM, Solano C, RodriguezHenríquez P, Hernández-Díaz C, Vargas A, et al. Joint and tendon subclinical involvement suggestive of gouty arthritis in asymptomatic hyperuricemia: an ultrasound controlled study. Arthritis Res Ther 2011; 13: R4.

17. Kawashima M, Wada K, Ohta H, Terawaki H, Aizawa Y. Association between asymptomatic hyperuricemia and new-onset chronic kidney disease in Japanese male workers: a long-term retrospective cohort study. BMC Nephrol 2011; 12: 31.

18. Vinik O, Wechalekar MD, Falzon L, Buchbinder R, van der Heijde DM, Bombardier C. Treatment of asymptomatic hyperuricemia for the prevention of gouty arthritis, renal disease, and cardiovascular events: a systematic literature review. J Rheumatol Suppl 2014; 92: 70-74.

19. Sircar D, Chatterjee S, Waikhom R, Golay V, Raychaudhury A, Chatterjee S, et al. Efficacy of Febuxostat for Slowing the GFR Decline in Patients With CKD and Asymptomatic Hyperuricemia: A 6-Month, Double-Blind, Randomized, Placebo-Controlled Trial. Am J Kidney Dis 2015; 66: 945-950. 
20. Qaseem A, Harris RP, Forciea MA. Management of Acute and Recurrent Gout: A Clinical Practice Guideline From the American College of Physicians. Ann Intern Med 2017; 166: 58-68.

21. Duskin-Bitan H, Cohen E, Goldberg E, Shochat T, Levi A, Garty M, et al. The degree of asymptomatic hyperuricemia and the risk of gout. A retrospective analysis of a large cohort. Clin Rheumatol 2014; 33: 549-553.

22. Dalbeth N, Bardin T, Doherty M, Lioté F, Richette P, Saag KG, et al. Discordant American College of Physicians and international rheumatology guidelines for gout management: consensus statement of the Gout, Hyperuricemia and CrystalAssociated Disease Network (G-CAN). Nat Rev Rheumatol 2017; 13: 561-568.

23. Al-Arfaj AS. Hyperuricemia in Saudi Arabia. Rheumatol Int 2001; 20: 61-64.
24. Mikuls TR, Farrar JT, Bilker WB, Fernandes S, Saag KG. Suboptimal physician adherence to quality indicators for the management of gout and asymptomatic hyperuricaemia: results from the UK General Practice Research Database (GPRD). Rheumatology (Oxford) 2005; 44: 1038-1042.

25. Bleyer AJ, Hart TC. Genetic factors associated with gout and hyperuricemia. Adv Chronic Kidney Dis 2006; 13: 124-130.

26. Pillinger MH, Rosenthal P, Abeles AM. Hyperuricemia and gout: new insights into pathogenesis and treatment. Bull NYU Hosp Jt Dis 2007; 65: 215-221.

27. Kuwabara M, Niwa K, Hisatome I, Nakagawa T, Roncal-Jimenez CA, Andres-Hernando A, et al. Asymptomatic Hyperuricemia Without Comorbidities Predicts Cardiometabolic Diseases: Five-Year Japanese Cohort Study. Hypertension 2017; 69: 1036-1044. 